\title{
Second Primary Malignancy in Bladder Carcinoma - A Population-based Study
}

\author{
AMIT KHANAL ${ }^{1}$, NIBASH BUDHATHOKI ${ }^{2}$, VIJAY PAL SINGH ${ }^{3}$ and BINAY K. SHAH ${ }^{4}$ \\ ${ }^{1}$ Section of Hematology and Oncology, Department of Medicine, \\ University of Illinois at Chicago, Chicago, IL, U.S.A.; \\ ${ }^{2}$ Interfaith Medical Center, Brooklyn, NY, U.S.A.; \\ ${ }^{3}$ American University of Antigua College of Medicine, Osbourn, Antigua; \\ ${ }^{4}$ North Puget Cancer Center, Sedro-Woolley, WA, U.S.A.
}

\begin{abstract}
Background: A second primary malignancy is a serious long-term complication in cancer survivors. The aim of this study was to evaluate the risk of second primary malignancies (SPM) in adult patients with bladder cancer. Materials and Methods: We selected patients $\geq 18$ years diagnosed with bladder cancer from National Cancer Institute's Surveillance, Epidemiology and End Results (SEER) 13 database. We calculated the risk of second primary malignancies in the bladder cancer patients using the MP-SIR session of SEER* stat software. Results: A total of 103,516 cases of bladder cancer was included in the study. Among them, 17,004 (16.4\%) developed 19,318 second primary malignancies. The risk of development of SPM was significantly higher compared to the general population with $O / E$ ratio of $1.42(95 \% C I=1.4-1.44, A E R=89.22$ and $p$-value of $<0.001)$. Prostate cancer, lung and bronchial cancer and urinary bladder cancer were the three commonest SPMs. Conclusion: There is significant increased risk of second primary malignancies in adult patients with bladder cancer to general population. Bladder cancer survivors may benefit from life-long follow-up for development of SPM.
\end{abstract}

Bladder cancer is the sixth commonest cancer with estimated 74,000 new cases in 2015 (1). Lifelong probability of developing invasive bladder cancer is 1 in 26 (2). Based on National Cancer Institute's Surveillance, Epidemiology, and End Results Program (SEER), the 5-year survival rate for bladder cancer is $77.5 \%$ (3). Survival rates are gradually improving, with increase from $74 \%$ to $82 \%$ from $1975-1977$

Correspondence to: Dr. Binay Kumar Shah, North Puget Cancer Center, 2000 Hospital Drive, Sedro-Woolley, WA 98284, U.S.A. Tel: +1 3608567588, Fax: +1 3608567252, e-mail: binay.shah@gmail.com

Key Words: Bladder cancer, second primary malignancy, SEER, latency. to $1999-2005$ ( $p$-value $<0.05)$ (2). It is important to investigate long-term complication of cancer, so the cancer survivors can be followed and managed appropriately. Second primary malignancy (SPM) is an important complication for cancer survivors $(4,5)$. In this population-based study, we investigated the risk of SPM in bladder cancer.

\section{Materials and Methods}

About the SEER database. The SEER program, sponsored by the US National Cancer Institute, collects comprehensive cancer data from hospitals and cancer treatment centers and maintains high quality data from defined geographical areas (6). The SEER program collects data on primary tumor site, stage of the tumor, patient demographics, surgery and/or radiotherapy and survival of patients. The SEER 13 includes 13 cancer registries, and represents $13.4 \%$ of the US population. The registries include: San FranciscoOakland Standard Metropolitan Statistical Area, Connecticut, Detroit (Metropolitan), Hawaii, Iowa, New Mexico, Seattle (Puget Sound), Utah, Atlanta (Metropolitan), San Jose-Monterey, Los Angeles, Alaska Natives, and Rural Georgia (7).

Study participants. We selected adult patients (18 years and older) with bladder carcinoma diagnosed during January 1992 to December 2012 from SEER 13 Regs Research Data, Nov 2014 Sub (1992-2012) database (8). We excluded cases diagnosed at autopsy and those who were lost to follow-up. Patients were followed-up from the diagnosis of bladder carcinoma to the date of last known vital status, death, or the last point of data collection. We included metachronous malignancy developing six months or more after an index bladder carcinoma as SPM (9).

Statistical analysis. We used the multiple primary standardized incidence ratio (MP-SIR) session of SEER stat software Version 8.1.5 March 26, 2014 for statistical analysis. We calculated the SIR, absolute excess risk and confidence interval for SPM in patients with bladder carcinoma by age (18-64 versus $\geq 65$ years), latency (6-59 versus $\geq 60$ months) and receipt of radiation. The SIR is also known as the relative risk. It is a relative measure of the strength of association between first primary and second primary malignancies. It is calculated by dividing the observed incidence of SPM by the 
expected incidence of SPM (O/E ratio) for the general population (10). Absolute excess risk (AER) is an absolute measure of the clinical burden of additional cancer occurrence in a given population. The AER is estimated by subtracting the expected number of second cancer cases from the observed number, dividing by the person-years at risk, and then multiplying by 10,000. Confidence intervals were calculated using Poisson distribution assumption

\section{Results}

A total of 103,516 cases of bladder cancer patients met the inclusion criteria. Majority of them were men $(75.89 \%)$. Median age of diagnosis was 70 years (24-104 years). The details of patient demography are shown in Table I. Of the 103,516 patients, $17,004(16.4 \%)$ developed 19,318 second primary malignancies. The risk of development of second primary malignancy among bladder cancer patient was significantly higher compared to general population with $\mathrm{O} / \mathrm{E}$ ratio of $1.42(95 \% \mathrm{CI}=1.4-1.44, \mathrm{AER}=89.22$ and $p<0.001)$. Median latency for development of second primary malignancy was 45 months (6-250 months).

Prostate cancer $(\mathrm{N}=3893, \mathrm{O} / \mathrm{E}=1.18,95 \% \mathrm{CI}=1.15-1.22$, $p \leq 0.001$, AER=9.42), lung and bronchial cancer $(\mathrm{N}=3831$, $\mathrm{O} / \mathrm{E}=1.87,95 \% \mathrm{CI}=1.81-1.93, p<0.001, \mathrm{AER}=27.8)$ and urinary bladder cancer $(\mathrm{N}=3113, \mathrm{O} / \mathrm{E}=2.99,95 \% \mathrm{CI}=2.89$ 3.1, $p=<0.001, \mathrm{AER}=32.34$ ) were the three commonest second primary malignancies in the cohort. We also found significantly increased risk of malignancies of esophagus, rectum, skin, kidney and renal pelvis cancer, ureteral cancer and acute leukemia among bladder cancer patients compared to general population (Table II).

Age and SPM. A total of 2,942 SPMs were diagnosed in patients of 18-64 years age group with $\mathrm{O} / \mathrm{E}$ ratio of 1.88 (95\% CI=1.81-1.95, $p \leq 0.001$ and AER=78.83). These patients had significant increase in the risk of malignancies of lung and bronchus $(\mathrm{N}=414, \mathrm{O} / \mathrm{E}$ ratio $=2.33,95 \% \mathrm{CI}=2.11$ 2.57, $p<0.001, \mathrm{AER}=13.55)$, prostate $(\mathrm{N}=716, \mathrm{O} / \mathrm{E}=1.61$, $95 \% \mathrm{CI}=1.5-1.74, p<0.001, \mathrm{AER}=15.61)$, urinary bladder $(\mathrm{N}=546, \quad \mathrm{O} / \mathrm{E}=7.79, \quad 95 \% \quad \mathrm{CI}=7.15-8.48, \quad p<0.001$, $\mathrm{AER}=27.29)$ and kidney and renal pelvis $(\mathrm{N}=185, \mathrm{O} / \mathrm{E}=3.15$, $95 \% \mathrm{CI}=2.72-3.64, p<0.001, \mathrm{AER}=7.24)$.

These patients also had significant increase in the risk of malignancies of thyroid $(\mathrm{N}=38, \mathrm{O} / \mathrm{E}$ ratio $=1.54,95 \% \mathrm{CI}=1.09$ 1.25, $\mathrm{AER}=0.28$ and $p=0.01)$, leukemia $(\mathrm{N}=51, \mathrm{O} / \mathrm{E}=1.41$, $95 \% \mathrm{CI}=1.05-1.85, \mathrm{AER}=0.58, p=0.02)$ and malignancies of digestive system except pancreaticobiliary $(\mathrm{N}=238, \mathrm{O} / \mathrm{E}=1.19$, 95\% $\mathrm{CI}=1.04-1.35, \mathrm{AER}=2.16$ and $p=0.01)$.

In the older age group ( $\geq 65$ years) a total of 16,376 cases of SPMs were diagnosed with $\mathrm{O} / \mathrm{E}$ ratio of 1.42 (95\% $\mathrm{CI}=1.4-$ 1.44, $p \leq 0.001$ and AER=93.16). These patients had significant increase in the risk of malignancies of lung and bronchus $(\mathrm{N}=3,417, \mathrm{O} / \mathrm{E}=1.83, \mathrm{CI}=1.77-1.89, \mathrm{AER}=33.15$,
Table I. Demographics of patients with SPM in Bladder Ca.

\begin{tabular}{lc}
\hline Characteristics & $\mathrm{N}(\%) /$ median(range) \\
\hline Total number of patients & 103,516 \\
Gender & \\
Male & $78,565(75.89 \%)$ \\
Female & $24,951(24.10 \%)$ \\
Race & \\
White & $77,358(89.62 \%)$ \\
Black & $4,995(4.82 \%)$ \\
Other & $5,741(5.54 \%)$ \\
Total number of SPM & 19,318 \\
Total number of patients with SPM & $17,004(16.4 \%)$ \\
Total number of patients with 1 SPM & 14,950 \\
Total number of patients with 2 or more SPMs & 2,054 \\
Age at the time of diagnosis of SPM, Years & 70 years $(24-104)$ \\
Latency to developing SPM, Months & 45 months $(6-250)$ \\
Follow up, months & 87 months $(6-251)$ \\
\hline
\end{tabular}

$p<0.001)$, prostate $(\mathrm{N}=3,177, \mathrm{O} / \mathrm{E}=1.12, \mathrm{CI}=1.08-1.16$, $\mathrm{AER}=7.11, p<0.001)$, urinary bladder $(\mathrm{N}=2,567, \mathrm{O} / \mathrm{E}=2.65$, $\mathrm{CI}=2.54-2.75, \mathrm{AER}=34.24, p<0.001)$, kidney and renal pelvis $(\mathrm{N}=725, \mathrm{O} / \mathrm{E}=2.11, \mathrm{CI}=1.96-2.27, \mathrm{AER}=8.2$ and $p<0.001)$. In addition, carcinoma of head and neck $(\mathrm{N}=399, \mathrm{O} / \mathrm{E}=1.19$, 95\% $\mathrm{CI}=1.04-1.35, \mathrm{AER}=0.08$ and $p=0.014)$ and digestive system except pancreaticobiliary system $(\mathrm{N}=1995, \mathrm{O} / \mathrm{E}=1.05$, 95\% $\mathrm{CI}=1.01-1.1, \mathrm{AER}=2.16$ and $p \leq 0.05)$ were significantly higher in this age group compared to the general population.

SPM and latency. The median latency period for development of SPM in patients with bladder cancer was 45 months (6-250 months).

Comparing the development of malignancies within five years of bladder cancer diagnosis against after five years of diagnosis showed that the malignancies of the lung and bronchus $(\mathrm{N}=1975$ vs. $\mathrm{N}=1856)$, urinary bladder $(\mathrm{N}=2065$ vs. $\mathrm{N}=1048)$, prostate $(\mathrm{N}=2555$ vs. $\mathrm{N}=1338)$, kidney and renal pelvis $(\mathrm{N}=535$ vs. $\mathrm{N}=375)$, the ureter $(\mathrm{N}=216$ vs. $\mathrm{N}=183)$ were significantly increased both during the first 5 years and after 5 years of diagnosis of bladder cancer.

Malignancies of small intestine $(\mathrm{N}=46, \mathrm{O} / \mathrm{E}=1.63, \mathrm{CI}=1.2-$ 2.18, $\mathrm{AER}=0.53, p=0.002)$, colon and rectum $(\mathrm{N}=890$, $\mathrm{O} / \mathrm{E}=1.13, \mathrm{CI}=1.05-1.2, \mathrm{AER}=2.98, p<0.001)$, pancreas $(\mathrm{N}=224, \mathrm{O} / \mathrm{E}=1.15, \mathrm{CI}=1-1.31, \mathrm{AER}=0.85, p=0.04)$, prostate $(\mathrm{N}=2,555, \mathrm{O} / \mathrm{E}=1.44, \mathrm{CI}=1.39-1.5, \mathrm{AER}=23.4, p<0.001)$, myeloid and monocytic leukemia $(\mathrm{N}=116, \mathrm{O} / \mathrm{E}=1.28$, $\mathrm{CI}=1.05-1.53, \mathrm{AER}=0.74, p<0.001)$ were increased within the first 5 years of diagnosis of bladder cancer.

After a latency of 5 years, malignancy of vagina $(\mathrm{N}=7$, $\mathrm{O} / \mathrm{E}=2.97, \mathrm{CI}=1.2-6.12, \mathrm{AER}=0.15, p<0.001)$ was significantly increased. Melanoma of the skin $(\mathrm{N}=211, \mathrm{O} / \mathrm{E}=0.71, \mathrm{CI}=0.62-$ $0.81, \mathrm{AER}=-2.83, p<0.001)$ and prostate cancer $(\mathrm{N}=1,338$, 
Table II. Second primary malignancies in patients with bladder carcinoma.

\begin{tabular}{|c|c|c|c|c|c|}
\hline \multirow[t]{2}{*}{ SPM } & \multicolumn{5}{|c|}{ Total, Persons at risk $=103,516$, Person years at risk $=640961.96$} \\
\hline & Observed & $\mathrm{O} / \mathrm{E}$ & $95 \% \mathrm{CI}$ & $p$-Value & Excess risk \\
\hline All sites & 19,318 & 1.42 & $1.4-1.44$ & $<0.001$ & 89.22 \\
\hline Head and neck & 488 & 1.15 & $1.05-1.25$ & 0.003 & 0.97 \\
\hline Digestive system except pancreaticobiliary & 2,233 & 1.06 & $1.02-1.11$ & 0.003 & 2.09 \\
\hline Esophagus & 212 & 1.18 & $1.02-1.35$ & 0.021 & 0.5 \\
\hline Rectum and rectosigmoid Junction & 434 & 1.13 & $1.03-1.24$ & 0.011 & 0.79 \\
\hline Pancreaticobiliary & 733 & 1.04 & $0.96-1.12$ & 0.325 & 0.42 \\
\hline Respiratory system & 3,860 & 1.86 & $1.8-1.92$ & $<0.001$ & 27.89 \\
\hline Bones and joints & 8 & 0.71 & $0.31-1.41$ & 0.429 & -0.05 \\
\hline Soft tissue including heart & 74 & 1.01 & $0.79-1.27$ & 0.976 & 0.01 \\
\hline Skin excluding basal and squamous & 545 & 0.84 & $0.78-0.92$ & $<0.001$ & -1.56 \\
\hline Breast & 618 & 0.97 & $0.9-1.05$ & 0.47 & -0.29 \\
\hline Female genital system & 230 & 0.96 & $0.84-1.09$ & 0.58 & -0.14 \\
\hline Male genital system & 3,941 & 1.19 & $1.15-1.22$ & $<0.001$ & 9.65 \\
\hline Prostate & 3,893 & 1.18 & $1.15-1.22$ & $<0.001$ & 9.42 \\
\hline Urinary system & 4,618 & 3.12 & $3.03-3.21$ & $<0.001$ & 48.92 \\
\hline Eye and orbit & 17 & 0.81 & $0.47-1.3$ & 0.466 & -0.06 \\
\hline Brain and other nervous system & 126 & 0.96 & $0.8-1.15$ & 0.728 & -0.07 \\
\hline Endocrine system & 117 & 1.16 & $0.96-1.38$ & 0.135 & 0.25 \\
\hline Lymphoma & 602 & 0.97 & $0.89-1.05$ & 0.481 & -0.28 \\
\hline Myeloma & 175 & 0.86 & $0.74-1$ & 0.054 & -0.43 \\
\hline Leukemia & 434 & 1.02 & $0.93-1.13$ & 0.633 & 0.16 \\
\hline Mesothelioma & 57 & 1.05 & $0.79-1.35$ & 0.77 & 0.04 \\
\hline Kaposi sarcoma & 8 & 0.69 & $0.3-1.36$ & 0.36 & -0.06 \\
\hline Miscellaneous & 434 & 1.36 & $1.23-1.49$ & $<0.001$ & 1.78 \\
\hline
\end{tabular}

$\mathrm{O} / \mathrm{E}=0.88, \quad \mathrm{CI}=0.83-0.93, \quad \mathrm{AER}=-5.98, \quad p<0.001) \quad$ were significantly decreased compared to the general population.

\section{Discussion}

American Cancer Society's report on "Cancer Treatment and Survivorship" estimates that there are 15.1 million cancer survivors living in the US in 2016 and are expected to increase to 20.3 million by 2026 (11). Increased survivorship has been attributed to several factors including early diagnosis, improvement in cancer specific therapy and supportive care. With increasing number of cancer survivors, it is important to address long term care and survivorship. Unfortunately, evidence-based management and follow up of cancer survivors is lacking (12). SPM is a serious and potentially fatal long-term complication in cancer patients (13). SPMs are common with an overall cumulative incidence of $14 \%$ at 25 years of follow-up (12).

In this population-based study, we report the risk of SPM's in patients with bladder cancer. Our study shows that patients with bladder cancer have $42 \%$ increase in risk of SPMs with an AER of 89 per 10,000. There was significant increase in cases of prostate cancer, lung and bronchial cancer and bladder cancer in the study population. Similar findings were found by Kotake $\mathrm{T}$ et al. where a significant increase in the relative risk of prostate cancer, following bladder cancer was reported (14). The study involved analysis of 372 reported cases in the Japanese literature, 36 of their own cases and 376 autopsy cases. Association between prostate cancer and urinary bladder cancer may be because patients are either highly susceptible to both cancers, or they might share a similar carcinogenic process such as DNA repair and $\mathrm{N}$-acetyltransferase polymorphism (15).

A study by Kellen $\mathrm{E}$ et al. found an excess risk of developing prostate cancer in bladder cancer in patients younger than 70 years and in the first year of follow-up after the diagnosis of bladder cancer (16).

Major risk factors for bladder cancer include cigarette smoke, napthylamine, azo dyes, and long term cyclophosphamide or phenacetin use (17). Cigarette smoking is a well known risk factor for cancer of lung and bronchus and head and neck region. The increase in risk of these cancers in patients with history of bladder cancer may be secondary to shared etiologies. Salminem and colleagues in their article showed an increase in incidence of lung cancer, larynx cancer in men, and kidney cancer among women who were first diagnosed with bladder cancer, and attributed this risk to smoking (18). A similar pattern was seen in our study 
for laryngeal cancer $(\mathrm{O} / \mathrm{E}=1.48)$ and lung and bronchial cancer $(\mathrm{O} / \mathrm{E}=1.76)$ in men and for kidney and renal pelvis cancer $(\mathrm{O} / \mathrm{E}=3.23)$ in females.

We also found significantly increased risk of malignancies of the renal pelvis, urinary bladder, and ureter among bladder cancer patients. This may be explained by the fact that bladder, renal pelvis, and ureter are lined by the same urothelial lining, and are predisposed to the same risk factors from the carcinogens in the urine. The study conducted in 1998 reported the risk of urinary tract cancers following kidney or ureter stones. It showed an increased risk of developing renal pelvis, ureter and bladder cancers, which may be due to chronic irritation and infections, eventually leading to cancer. Study showed significantly excess risk of renal pelvis/ureter cancer $(\mathrm{SIR}=2.5 ; 95 \% \mathrm{CI}=1.8-3.3)$ and bladder cancer $(\mathrm{SIR}=1.4 ; 95 \% \mathrm{CI}=1.3-1.6)$ (19). Similar underlying pathophysiology for development of urinary tract cancer in our patient might have been present.

The strengths of this study include its large sample size and long-term follow-up. The limitations of the study are related to the use of population-based registries. Surveillance, Epidemiology, and End Result (SEER) database does not have comorbidities, lifestyle and risk factors, environmental exposure, and family history. SEER database does not have information on chemotherapy used. We were unable to analyze SPM by stage, because collaborative stage is not used for cases diagnosed prior to 2004.

\section{References}

1 Siegel RL, Miller KD and Jemal A: Cancer statistics, 2015. CA Cancer J Clin 65(1): 5-29, 2015.

2 Jemal A, Siegel R, Xu J and Ward E: Cancer statistics, 2010. CA Cancer J Clin 60(5): 277-300, 2010.

3 Howlader N, Noone AM, Krapcho M, Miller D, Bishop K, Altekruse SF, Kosary CL, Yu M, Ruhl J, Tatalovich Z, Mariotto A, Lewis DR, Chen HS, Feuer EJ, Cronin KA (eds.). SEER Cancer Statistics Review, 1975-2013, National Cancer Institute. Bethesda, MD, http://seer.cancer.gov/csr/1975_2013/, based on November 2015 SEER data submission, posted to the SEER web site, April 2016.

4 Shah BK and Budhathoki N: Second primary malignancy in anal carcinoma - a us population-based study. Anticancer Res 35(7): 4131-4134, 2015.

5 Shah BK and Budhathoki N: Second primary malignancy in burkitt's lymphoma. Acta Oncol 55(3): 396-398, 2016.

$6 \mathrm{Https}: / /$ seer.Cancer.Gov/registries/ accession date: 12/31/2016.
7 http://seer.cancer.gov/data/metadata.html.

8 Surveillance, Epidemiology, and End Results (SEER) Program (www.seer.cancer.gov) SEER*Stat Database: Incidence - SEER 13 Regs Research Data, Nov 2014 Sub (1992-2012) <Katrina/Rita Population Adjustment $>$ - Linked To County Attributes - Total U.S., 1969-2013 Counties, National Cancer Institute, DCCPS, Surveillance Research Program, Surveillance Systems Branch, released April 2015, based on the November 2014 submission.

9 Warren S and Gates O: Multiple primary malignant tumors: A survey of the literature and a statistical study. Am J Cancer 16: 1358-1414, 1932.

10 Schoenberg BS and Myers MH: Statistical methods for studying multiple primary malignant neoplasms. Cancer 40(4 Suppl): 1892-1898, 1977.

11 Miller KD, Siegel RL, Lin CC, Mariotto AB, Kramer JL, Rowland JH, Stein KD, Alteri R and Jemal A: Cancer treatment and survivorship statistics, 2016. CA Cancer J Clin 66(4): 271$289,2016$.

12 From Cancer Patient to Cancer Survivor. Lost in transition. Washington, D.C.: Instintue of medicine and National research council.

13 Donin N, Filson C, Drakaki A, Tan HJ, Castillo A, Kwan L, Litwin $\mathrm{M}$ and Chamie K: Risk of second primary malignancies among cancer survivors in the united states, 1992 through 2008. Cancer 122(19): 3075-3086, 2016.

14 Kotake $\mathrm{T}$ and Kiyohara H: Multiple primary cancers $(\mathrm{mpc})$ associated with bladder cancer: An analysis of the clinical and autopsy cases in japan. Jpn J Clin Oncol 15(Suppl 1): 201-210, 1985.

15 Kinoshita Y, Singh A, Rovito PM Jr., Wang CY and Haas GP: Double primary cancers of the prostate and bladder: A literature review. Clin Prostate Cancer 3(2): 83-86, 2004.

16 Kellen E, Zeegers MP, Dirx M, Houterman S, Droste J, Lawrence G, Truyers C, Bruckers L, Molenberghs G, Joniau S and Buntinx F: Occurrence of both bladder and prostate cancer in five cancer registries in belgium, the netherlands and the united kingdom. Eur J Cancer 43(11): 1694-1700, 2007.

17 Dawson $\mathrm{C}$ and Whitfield $\mathrm{H}$ : Abc of urology. Urological malignancy--1: Prostate cancer. BMJ 312(7037): 1032-1034, 1996.

18 Salminen E, Pukkala E and Teppo L: Bladder cancer and the risk of smoking-related cancers during followup. J Urol 152(5 Pt 1): 1420-1423, 1994.

19 Chow WH, Lindblad P, Gridley G, Nyren O, McLaughlin JK, Linet MS, Pennello GA, Adami HO and Fraumeni JF Jr.: Risk of urinary tract cancers following kidney or ureter stones. J Natl Cancer Inst 89(19): 1453-1457, 1997.

Received February 13, 2017

Revised March 1, 2017

Accepted March 2, 2017 